\title{
Prevalence of Dental Fluorosis in a City without Fluoridation in its Water Supply: Effect of Sampling
}

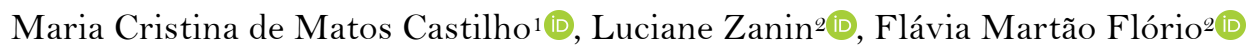

${ }^{1}$ Pos-Graduate Program, Department of Public Health, São Leopoldo Mandic School, Campinas, SP, Brazil.

${ }^{2}$ Department of Public Health Dentistry, São Leopoldo Mandic School, Campinas, SP, Brazil.

Author to whom correspondence should be addressed: Flávia Martão Flório, Rua José Rocha Junqueira, 13, Ponte Preta, Campinas, São Paulo, Brazil. 13045-755. Phone: +55 19 99908-7533. E-mail: flaviaflorio@yahoo.com.

Academic Editors: Alessandro Leite Cavalcanti and Wilton Wilney Nascimento Padilha

Received: 12 September 2019 / Accepted: 20 March 2020 / Published: 08 April 2020

How to cite this article: Castilho MCM, Zanin L, Flório FM. Prevalence of dental fluorosis in a city without fluoridation in its water supply: effect of sampling. Pesqui Bras Odontopediatria Clín Integr. 2020; $20: e 5214$. https://doi.org/10.1590/pboci.2020.063

\begin{abstract}
Objective: To determine the prevalence of dental fluorosis in a population not exposed to fluoridated water and to evaluate the effect of the sampling technique on this measurement. Material and Methods: This observational, cross-sectional and quantitative study was conducted in the city of Mariana, Brazil. The participants were selected based on age, so that they had access to fluoridated dentifrice during the formation of the permanent upper teeth. Based on a nominal survey of schoolchildren aged 14 to 19 , a probabilistic sample of 304 such children was clinically examined. Dental fluorosis was measured by the Thylstrup-Fejerskov index. The prevalence of fluorosis identified in a previous study, conducted in 2011 in the same city, using the same methodology but employing convenience sampling, was used as a control to compare the effect of the two sampling techniques. Results: The prevalence of dental fluorosis was $3 \%$ based on the probabilistic sampling of the subjects. In the previous study, the prevalence of fluorosis was $7 \%$ $(\mathrm{p}<0.05)$ based on convenience sampling of the same age group. Both studies detected a ThylstrupFejerskov fluorosis index value of 1, corresponding to only a mild degree of dental fluorosis. Conclusion: The convenience sampling technique seems to have affected the prevalence of dental fluorosis identified, with a $4 \%$ difference between the two studies. The prevalence of dental fluorosis attributed to the use of fluoridated dentifrice in a population not exposed to fluoridation of the water supply was considered low.
\end{abstract}

Keywords: Epidemiologic Studies; Cross-Sectional Studies; Fluorosis, Dental; Dentifrices. 


\section{Introduction}

Dentifrice is the most widely used method of fluoride application [1-3]. Fluoridated dentifrices are used almost universally in economically developed countries [4,5], and are undoubtedly responsible for the reduction in dental caries rates [2,5-8].

The large-scale availability of fluoridated dentifrices, which began in 1989, along with the fluoridation of the water supply and the expansion of preventive programs in schools, are the three main reasons for the decline in dental caries in Brazil [9]. The country is among the nations that most consume fluoridated dentifrices, behind only the USA [10], and 89.1\% of adults brush their teeth at least twice a day [11].

In addition to its usefulness for the control of dental caries, there are some undesirable side effects of excessive exposure to fluoridated dentifrices [7,8,12], such as dental fluorosis (DF) [1,13,14]. This is the hypomineralization of enamel or dentin produced by chronic ingestion of fluoride during the tooth development period $[8,15]$. Its severity is related to the occasion, duration and dose of fluoride exposure [16]. Exposure during the post secretory or early maturation period of enamel development can pose a higher risk of fluorosis [8]. The teeth of greatest aesthetic concern, the permanent central incisors, appear to be at greater risk of DF when fluoride is ingested during the first 36 months of life [17].

A global increase in the prevalence of DF has been reported over the last forty years [18,19], irrespective of the presence of fluoride in the supply water $[2,8,20]$. Several studies associate this rise with the unintentional intake of fluoride from sources other than drinking water, such as the use of dentifrice in the first three years of life $[12,13]$.

According to some authors, diet and toothpastes are considered the most representative sources of fluoride, with dentifrice the greatest source of total fluoride intake [21]. There is, however, considerable controversy about the role of fluoridated dentifrices in determining DF. The findings of some studies were not conclusive in associating the use of such dentifrices with DF [3,22,23], while others identified them as a risk factor $[17,24]$.

A survey of literature found great variability in the prevalence of DF in several countries. However, the studies surveyed differed in the fluorosis indexes used, the sample type and size, the evaluation methodology, and the fluoride content to which the evaluated populations were subjected, making it difficult to compare their results. In Brazil, a variation in prevalence of between 0\% [25] and 29.2\% [26] has been observed in localities without fluoridation of the public water supply. Brazilian data from 2003 revealed a prevalence of mild and very mild degrees of DF of 5.1\% for adolescents aged 15-19 years and 8.6\% for those aged twelve years [27]. In 2010, only 12-year-old children were evaluated, among whom the prevalence was $16.7 \%$, also of mild or very mild cases [28]. A recent systematic review that also considered Brazilian regions with a non-fluoridated water supply (less than $0.2 \mathrm{ppm} \mathrm{F}$ ), found that the prevalence of DF ranged from $0.56 \%$ to $40 \%$ [29], while a systematic review in 2016 [30] involving studies in other countries found an average prevalence of DF of $12.9 \%$ in a population aged 6-18 years of age exposed to water fluoridated at concentrations below 0.7 ppm.

The fluoride intake of a population and consequently, the prevalence of DF may change over time, and exposure to fluoride and DF prevalence should, therefore, be monitored by periodic surveys [31]. Previous authors found that the prevalence of DF attributed to the use of fluoridated dentifrices in the city of Mariana, in the state of Minas Gerais, Brazil, which still does not have fluoridation in its public water supply, was $7 \%$ [32]. The sample size was calculated based on statistical methods, but the participants were allocated by the 
criterion of proximity to the examination site, in the central area of the town, where banks and commerce are located, and included people from all neighborhoods.

Among the many factors that can influence the results of epidemiological surveys are the sampling methods, the size of the sample and the extent to which it is representative of the population studied [33], as the effects of selection factors associated with the inclusion of subjects in studies may seriously limit the generalization of results [34]. The accuracy of the conclusions of epidemiological studies will depend on how well the samples are collected and how representative they are [33].

Sampling for convenience is a non-probabilistic technique, in which the researcher selects the elements to be included based on subjective methods [35]. It is considered a weak technique as it may be less representative and can lead to bias [36]. Randomization of the population of interest is not a priority in this technique [35]. Probabilistic sampling is that which is obtained by a method that uses some form of random selection, guaranteeing that the different units in a population have an equal probability of being chosen [37]. It provides greater reliability since there is no possibility of bias in selection [38,39].

Considering the above, following a previous study [32], it was necessary to determine the prevalence of $\mathrm{DF}$ in a population not exposed to fluoridated water and to evaluate the effect of the sampling technique on this measure.

\section{Material and Methods}

Study Design

A cross-sectional and quantitative observational study was carried out in the city of Mariana, located in the southeast of the state of Minas Gerais, $116 \mathrm{~km}$ from the state capital. According to the Brazilian Institute of Geography and Statistics [40] in the 2010 demographic census, the population was 54,219 inhabitants, with an average Municipal Human Development Index (HDI) of 0.742.

Electrometric analysis of the fluoride content of all the water sources in the city found negligible levels of this element in the local water supply [32].

\section{Sampling}

The sample of the present study was probabilistic, with the target population made up of students of the public and private education system of Mariana. To calculate the sample size, the proportion of individuals with DF found in the previous study [32] was used, with a confidence level of $95 \%$, an accuracy of $10 \%$, adjustment for a finite population $(\mathrm{n}=3109)$ and a design effect (deff) of 2 , identifying a minimum sample of 297 students. A further $20 \%$ was added in order to compensate for possible losses and refusals, resulting in a sample size of 356 .

Considering that fluoride has been present in almost all Brazilian dentifrices since 1989 [9], participants were selected based on their age on December 31, 2014, i.e., those born between January 1, 1995 and December 31, December 2000 (and therefore aged between 14 and 19 years) were chosen. During the formation of the permanent upper anterior teeth, namely o to 3 years of age [17], they used dentifrice with fluoride [9]. Since the prevalence of DF was equal for both genders [41], equal gender distribution was not sought among those examined.

Data Collection 
Following approval of the study, the Municipal Education Department of Mariana provided a list of the municipal, state and private schools in the city. A nominal report with the date of birth and grade of students in the age group of interest was requested from each school principal. A single list of students was drawn up, with the order of the schools drawn by lots to allow the numbering of individuals. The students were numbered from 1 to 3,109 and a second draw was performed using the www.sorteador.com.br website, where it was possible to draw 356 numbers from 1 to 3109 in their respective fields, obtaining the list of students to be examined and their corresponding schools. The next step was to establish contact with those selected and obtain their agreement to participate in the study, along with that of their parents or guardians.

Place of birth and residence up to three years of age was considered as an inclusion criterion, based on the fact that the critical period for the development of DF in the upper anterior permanent teeth is from the $1 \mathrm{st}$ to the 3rd year of life [17]. The participants were required to have been born and lived from birth to three years of age in the city of Mariana, thereby discarding the fluoride effect of water on the occurrence of DF. Of the students selected, 12 did not meet this criterion, eight refused to participate and eight missed the appointment. Ten individuals with anodontia, extensive restoration or widespread caries were excluded, along with 14 with orthodontic appliances in the anterior superior teeth, which made the diagnosis of DF impractical.

The examiner underwent training and calibration in the diagnosis of DF by an experienced trainer until there was an agreement between the two of over $85 \%$. To ensure intra-examiner agreement, duplicate examinations were performed before and during the survey. Previously, 35 volunteers who were not part of the sample were examined twice, testing the classification in the first and second examinations. There was $100 \%$ agreement. During the survey, $10 \%$ of the sample was selected for reexamination by the drawing of lots, without the examiner's knowledge. The agreement between the diagnosis of the first and second exams in the same participants was $100 \%$.

The students were scheduled for oral examination at the office of the researcher in Mariana, Minas Gerais, between December 2014 and April 2015 and classified according to the appearance of the vestibular enamel of the upper anterior teeth. A score was recorded for each tooth examined, using the ThylstrupFejerskov index [42] for DF measurement. The examination was performed on different days and times, in a dentist's chair, with a reflector light, after cleaning with gauze if necessary, and air-drying of the teeth for 1 to 2 minutes. When the need for dental treatment was observed, the student or their caregiver was informed and the child was referred for treatment in the municipal public service.

\section{Data Analysis}

Initially, the prevalence of DF was estimated with respective confidence intervals of $5 \%$. Next, the Chi-squared test was applied comparing the prevalence calculated by probabilistic and non-probabilistic sampling. The SAS program (SAS Institute Inc., Cary, NC, USA, Release 9.2, 2010) was used for analysis and the level of significance was $5 \%$.

\section{Ethical Aspects}

The study complied with the precepts determined by Resolution No. 466 dated 2012 of the Brazilian Health Council of the Ministry of Health and was approved by the Ethics Research Committee of Plataforma Brasil, of the Ministry of Health, under CAAE 32281513.7.0000.5374.

\section{Results}


Of the 356 students, the sample loss was $14.6 \%(\mathrm{n}=52)$. Of the remaining total of 304,279 students $(91.8 \%)$ were enrolled in the public-school system and 25 (8.2\%) were enrolled in private schools. From this sample, nine presented DF, all of whom had aTF score $=1$, representing a prevalence of $3.0 \%$. The DF detected occurred in a total of 41 teeth.

Table 1 shows that the prevalence of DF in the probabilistic sample was $3.0 \%$ (CI 95\%: 1.1-4.9), while in the non-probabilistic sample, it was $7.0 \%$ (CI 95\%: 3.4-10.5), with a significant difference between the samples $(\mathrm{p}=0.034)$.

Table 1. Prevalence of dental fluorosis in probabilistic and non-probabilistic samples.

\begin{tabular}{lcccccc}
\hline \multirow{2}{*}{ Sample } & \multicolumn{1}{c}{ Total } & No & Yes & Prevalence & CI 95\%* & p-value \\
& N $(\%)$ & N $(\%)$ & N $(\%)$ & & & \\
\hline Probabilistic & $304(100.0)$ & $295(97.0)$ & $9(3.0)$ & $3 \%$ & $1.1-4.9$ & 0.034 \\
Non-probabilistic & $201(100.0)$ & $187(93.0)$ & $14(7.0)$ & $7 \%$ & $3.4-10.5$ & \\
\hline
\end{tabular}

${ }^{8}$ Confidence Interval of $95 \%$ of prevalence of fluorosis.

\section{Discussion}

Using probabilistic sampling, the present study identified a prevalence of DF in schoolchildren in the city of Mariana of $3 \%$. To evaluate the effect of the sampling technique on the prevalence of DF, the aim was to compare the results obtained through the use of random sampling with a previous study [32], which was carried out in the same locality and employed convenience sampling. The present study attempted to replicate the methodology of the previous work, the objective of which was to verify the effect of fluoridated dentifrices on the prevalence of DF in a region with non-fluoridated water. It was found that the sampling technique appeared to have affected the prevalence of DF identified in the same population in the previous study [32].

The WHO recommends that the presence of DF is registered, even though it is not considered a disease. Such registration helps countries to establish prevention programs that include fluoride [33]. The importance of epidemiological surveys in cities without fluoride in their water supply was previously emphasized [43]. Such populations can represent a gold standard in studies that jointly contemplate other locations where fluoride is effectively present in drinking water. These allow parameters of comparison regarding the anti-cariogenic benefits and possible side effects of continuous consumption to be established. Studying a city without fluoride in its water supply is also useful for evaluating the influence of other methods through which this ion may be a causal factor of DF.

Studies of the prevalence of DF in Brazil present great variability in terms of the method and indices used, the results indicated, and the age range of the samples. The selection criteria for samples are often not cited nor described in detail. Due to the peculiarities of each study, the variable exposures to fluoride through sources other than water are specific to each community and difficult to measure, making establishing comparisons between them a complex task. Nevertheless, the degree of exposure of a community to fluoride and the consequent risk of DF are often assessed through comparisons between previous results and periodic surveys.

With this caveat, Brazilian studies in locations without water fluoridation at the time of the survey were compared and a prevalence of $0 \%$ [25] to $29.2 \%$ [26] was found. The prevalence of DF obtained in Mariana was considered low, while the lowest value was found in Cabo Frio (Rio de Janeiro, Brazil) [25], in a sample of adolescents aged 15 years, and the highest value was identified in João Pessoa (Paraiba, Brazil) [26], 
in adolescents aged 12 to 15 years. Both studies used a random sample and the Dean index for the evaluation of DF.

Similar values were obtained in Giruá and Agudo (Rio Grande do Sul, Brazil) (0.5\% and 0.6\%, respectively) [44] with the $\mathrm{TF}$ index and, also by the São Paulo State Department [45], which found a prevalence of $0.66 \%$ for children aged 12 years old and $0.44 \%$ for young people aged from 15 to 19 years old, using a probabilistic sample and the Dean index. In Itápolis (São Paulo, Brazil) [46], a prevalence of 1.7\% was found in people aged 5 to 24 years old [46], with the TF index. The prevalence recorded by the São Paulo State Department in 1998 was 4.9\% [47], higher than that of 2002 and closer to the present study and to that described by other authors [23], which found a prevalence of $5.21 \%$ in three cities in São Paulo. The two studies cited used random samples.

Also using a random sample and the Dean index, previous authors reported a prevalence of DF of 6.2 $\%$ [48], while another study revealed a prevalence of $7.5 \%$, in a sample aged 6 to 12 years [49], lower than the age of the Mariana sample, but with the same evaluation index.

In Ouro Preto (Minas Gerais), some authors found a prevalence of DF of $11.4 \%$ using the Dean index [50], which they considered high, similar to that of cities with fluoridated water. However, there may have been a fluoride contribution from air pollution from an aluminum plant at the time. Water from the springs that serve the public supply and those scattered around the city, where people usually ingest water or fill gallon tanks to take home, was not tested. These factors, in addition to the halo effect, which was not considered, may have been responsible for this higher value.

In São João de Petrópolis (Espírito Santo, Brazil), the DF value verified was 16\% [51]. Finally, as mentioned, João Pessoa (Paraíba, Brazil) [26] recorded the highest value among those cited, 29.2\%. It was observed that the prevalence of DF in Mariana is within the range of values detected in Brazilian studies conducted in localities without fluoride in the water supply. In qualitative terms, the DF results in Mariana were mild, a result considered likely, as the water of the city does not contain fluoride. Cases of DF in localities without fluoridation of the public water supply, for the most part, are classified as mild, very mild or moderate, and are often detected only with suitable clinical examination methodologies [23], necessitating both proximity and the drying of the teeth with air [17], both of which occurred in this study. Thus, the DF detected was not an aesthetic problem, nor a public health issue. Among Brazilian adolescents, carious lesions more negatively impact quality of life than the presence of DF [52].

When the prevalence of DF in the present study (3.0\%) was compared with that reported previously $(7 \%)$ [32], it was noted that the sampling technique seems to have influenced the quantitative results. Sampling selection methods are known to affect the interpretation of study results and may severely limit their generalization [34]. Convenience sampling has certain limitations that prevent the researcher from drawing conclusions about a population [35], but the probabilistic sample avoids selection bias [33] and makes it possible to generalize from the sample to the reference population with a known degree of accuracy [38]. The probabilistic sample used in the current study represented the studied population, and the prevalence observed should be similar to that of a population with the same epidemiological and socioeconomic characteristics. Therefore a random sampling technique should be chosen where possible.

One fact that may have contributed to the difference in quantitative results, in addition to the sampling technique, obviously, is that almost all the studies where probabilistic sampling was used (91.8\%) were carried out in public schools, where the socio-cultural level of students and their parents may be lower. The convenience sample, on the other hand, was obtained from the central region, near the most expensive 
private college in the city, many of whose students were included in the study. There may, therefore, have been socioeconomic variations between the individuals of the two samples, which, although not analyzed, could have influenced the results. Parents with higher educational and socioeconomic levels tend to take better care of their children's oral health, including brushing of teeth [53], which could favor the occurrence of DF. As a consequence, it is suggested that comparative studies of DF take into account the socioeconomic level of the population, since differences in the same may interfere with the results.

As the index used for DF measurement was the same for all the individuals examined in the two studies in Mariana, the results of both surveys were equal in qualitative terms. Data collected by questionnaires answered by mothers in the first study [32] revealed that almost all of the sample consumed the public water supply. There was no habit of consuming bottled mineral water and no fluoride was obtained from supplements or industrialized soups or baby food. The children's meals were prepared at home. There was no reference to participation in school programs that used fluoride. Between birth and three years of age, an important period for the development of DF, 95\% of the children started brushing with fluoride dentifrice. Thus, the findings related to DF can be attributed to the use of fluoridated dentifrices. It is known that the most important risk factor for DF is the amount of fluoride ingested during the critical period of tooth formation [18]. As fluoridation of water is not provided in many places, dentifrices may be the most important source of fluoride, as was the case in Mariana [21,54].

One limitation was the four-year gap between the present study and the study that served as a basis of comparison when, ideally, both studies should have been performed simultaneously. However, care with the composition of the sample group may have minimized this limitation, given the equal conditions of access to fluoride during the formation phase of the permanent dentition. Another unfavorable factor was that the questionnaires were not applied a second time to the mothers of the students examined to verify the consumption of dentifrices in the first years of life of the participants.

The low prevalence of mild intensity DF, ratified by several studies around the world and verified in the present work, the remarkable inhibitory effect of dental caries [2], and the ease of application and low cost of fluoridated dentifrices support the correct use of such products and make them indispensable for the maintenance of oral health. Guidelines can minimize risk and increase safety. The American Academy of Pediatric Dentistry [6] recommends the use of fluoridated toothpastes from the eruption of the first tooth. In children under three years of age, a smear of toothpaste on the toothbrush should be used, and brushing limited to twice a day. Children over three years of age should use a pea-sized quantity of toothpaste. Furthermore, some authors warn of the need to supervise and help young children with brushing [6]. The mouth should not be rinsed after brushing. Spitting out excess paste without rinsing with water reduces the amount of dentifrice ingested and leaves some fluoride in the saliva to be absorbed by the dental plaque. It is also important to keep all dental products out of the reach of children, avoiding accidental ingestion.

\section{Conclusion}

The convenience sampling technique seems to have affected the prevalence of dental fluorosis identified, with a $4 \%$ difference between the two studies. The prevalence of dental fluorosis attributed to the use of fluoridated dentifrice in a population not exposed to fluoridation of the water supply was considered low.

\section{Authors' Contributions}

MCMC (D) 0000-0003-1157-3253 Conceptualization, Methodology, Investigation, Formal Analysis, Writing Original Draft Preparation and Writing - Review and Editing. 
LZ (D) 0000-0003-02 18-9313 Writing - Original Draft Preparation and Writing - Review and Editing.

FMF (D) 0000-0001-7742-0255 Project Administration, Supervision and Writing - Review and Editing.

All authors declare that they contributed to critical review of intellectual content and approval of the final version to be published.

\section{Financial Support}

None.

\section{Conflict of Interest}

The authors declare no conflicts of interest.

\section{Acknowledgments}

The authors would like to thank the Municipal Education Secretary of Mariana, Minas Gerais, for permission to implement the study in schools, as well as the principals, employees and teachers of the schools, especially teachers Edna Barbosa, Isabel Jesus Ferreira and Carvalho and Silvana Nascimento da Cruz, for their inestimable collaboration during the undertaking of the study. We would also like to thank all the students who participated in the study.

\section{References}

[1] O'Mullane DM, Ketley CE, Cochran JA, Whelton HP, Holbrook WP, van Loveren C, et al. Fluoride ingestion from toothpaste: Conclusions of European Union-funded multicentre project. Community Dent Oral Epidemiol 2004; 32(Supply 1):74-6. https://doi.org/10.1111/j.1600-0528.2004.00143.x

[2] Marinho VC, Higgins JP, Sheiham A, Logan S. Fluoride toothpastes for preventing dental caries in children and adolescents. Cochrane Database Syst Rev 2003; (1):CD002278. https://doi.org/10.1002/14651858.CDo02278

[3] Wong MC, Clarkson J, Glenny AM, Lo EC, Marinho VC, Tsang BW, et al. Cochrane reviews on the benefits/risks of fluoride toothpastes. J Dent Res 2011; 90(5):573-9. https://doi.org/10.1177/0022034510393346

[4] O'Mullane DM, Baez RJ, Jones S, Lennon MA, Petersen PE, Rugg-Gunn AJ, et als. Fluoride and oral health. Community Dental Health 2016; 33(2):69-99.

[5] Walsh T, Worthington HV, Glenny AM, Marinho VC, Jeroncic A. Fluoride toothpastes of different concentrations for preventing dental caries. Cochrane Database Syst Rev 2019; 3:CDo07868. https://doi.org/10.1002/14651858.CDo07868.pub3

[6] Clark MB, Slayton RL, Section on Oral Health. Fluoride use in caries prevention in the primary care setting. Pediatrics 2014; 134(3):626-33. https://doi.org/10.1542/peds.2014-1699

[7] Petersen PE, Ogawa H. Prevention of dental caries through the use of fluoride - the WHO approach. Community Dental Health 2016; 33:66-8. https://doi.org/10.1922/CDH_Petersen03

[8] Whelton HP, Spencer AJ, Do LG, Rugg-Gunn AJ. Fluoride revolution and dental caries: evolution of policies for global use. J Dent Res 2019; 98(8):837-46. https://doi.org/10.1177/0022034519843495

[9] Cury JA, Tenuta LMA, Ribeiro CCC, Paes Leme AF. The importance of fluoride dentifrices to the current dental caries prevalence in Brazil. Braz Dent J 2004; 15(3):167-74. https://doi.org/10.1590/So 103-64402004000300001

[10] Brasil. Agência Brasileira de Desenvolvimento Industrial. Estudo Prospectivo. Indústria de Higiene Pessoal Perfumaria e Cosméticos. Série Cadernos da Indústria ABDI Brasília: Vol XIII; 2009. Available from: http://www.abdi.com.br/Estudo/XIII.pdf. [Accessed on April 14, 2019] [In Portuguese].

[11] Brasil. Instituto Brasileiro de Geografia e Estatística. Pesquisa Nacional de Sáude 2013. Saúde Bucal: 62. Available from: http://biblioteca.ibge.gov.br/visualizacao/livros/liv91110.pdf. [Accessed on April 14, 2019] [In Portuguese].

[12] Angulo M, Cuitiño E, Molina-Frechero N, Emilson CG. The association between the prevalence of dental fluorosis and the socio-economic status and area of residence of 12-year-old students in Uruguay. Acta Odontol Scand 2020; 78(1):26-30. https://doi.org/10.1080/00016357.2019.1642514

[13] Do LG, Spencer AJ. Risk-benefit balance in the use of fluoride among young children. J Dent Res 2007; 86(8):723-8. https://doi.org/10.1177/154405910708600807

[14] Raghavan R, Bipin N, Abraham A. Prevalence of dental fluorosis and fluoride content of drinking water in rural areas of Malappuram district, Kerala. Int $\mathrm{J}$ Med Sci Public Health 2014; 3(1):27-30. https://doi.org/10.5455/ijmsph.2013.200920132

[15] Horowitz HS. Fluoride and enamel defects. Adv Dent Res 1989; 3(2):143-6.

[16] Bronckers ALJJ, Lyaruu DM, DenBesten PK. The impact of fluoride on ameloblasts and the mechanisms of enamel fluorosis. J Dent Res 2009; 88(10):877-893. https://doi.org/10.1177/0022034509343280

[17] Franzman MR, Levy SM, Warren JJ, Broffitt B. Fluoride dentifrice ingestion and fluorosis of the permanent incisors. J Am Dent Assoc 2006; 137(5):645-52. https://doi.org/10.14219/jada.archive.2006.0261 
[18] Mascarenhas AK. Risk factors for dental fluorosis: a review of the recent literature. Pediatric Dent 2000; 22(4):26977.

[19] Martinez-Mier EA, Shone DB, Buckley CM, Ando M, Lippert F, Soto-Rojas AE. Relationship between enamel fluorosis severity and fluoride content. J Dent 2016; 46:42-6. https://doi.org/10.1016/j.jdent.2016.01.007

[20] Lee GH, Pang HN, McGrath C, Yiu CK. Oral health of Hong Kong children: a historical and epidemiological perspective. Hong Kong Med J 2016; 22(4):372-81. https://doi.org/10.12809/hkmj154686

[21] Lima-Arsati YBO, Gomes ARLF, Santos HKA, Arsati F, Oliveira MC, Freitas VS. Exposure to fluoride of children during the critical age for dental fluorosis, in the semiarid region of Brazil. Cien Saúde Coletiva 2018; 23(4):1045-54. https://doi.org/10.1590/1413-81232018234.07952016

[22] Pendrys DG, Katz RV. Risk of enamel fluorosis associated with fluoride supplementation, infant formula, and fluoride dentifrice use. Am J Epidemiol 1989; 130(6):1199-208. https://doi.org/10.1093/oxfordjournals.aje.a1 15448

[23] Jordão MRA. Influência do dentifrício fluoretado na prevalência de fluorose dental no Brasil. [Dissertation]. Piracicaba: Universidade Estadual de Campinas; 2002. [In Portuguese].

[24] Osujp OO, Leake JL, Chipman ML, Nikiforuk G, Locker D, Levine N. Risk factors for dental fluorosis in a fluoridated community. J Dent Res 1988; 67(12):1488-92. https://doi.org/10.1177/00220345880670120901

[25] Uchôa H, Melo MLT, Lopes ES, Guimarães LO, Chianca TK. Fluoração do sal de consumo humano no município de Cabo Frio - RJ. Rev Bras Odontol 1993; 50(2):49-56. [In Portuguese].

[26] Carvalho TS, Kehrle HM, Sampaio FC. Prevalence and severity of dental fluorosis among students from João Pessoa, PB, Brazil. Braz Oral Res 2007; 21(3):198-203. https://doi.org/10.1590/S1806-83242007000300002

[27] Brasil. Ministério da Saúde. Secretaria de Políticas de Saúde. Departamento de Atenção Básica. Área Técnica de Saúde Bucal. Projeto SB 2003: Condições de Saúde Bucal da População Brasileira no Ano de 2002-2003. Brasília: Ministério da Saúde; 2004. pp.54-55. [In Portuguese].

[28] Brasil. Ministério da Saúde. Secretaria de Atenção à Saúde. Secretaria de Vigilância em Saúde. SB Brasil 2010: Pesquisa Nacional de Saúde Bucal: Resultados Principais. Brasília: Ministério da Saúde; 2012. 47pp. [In Portuguese].

[29] Lima IFP, Nóbrega DF, Cericato GO, Ziegelmann PK, Paranhos LR. Prevalence of dental fluorosis in regions supplied with non-fluoridated water in the Brazilian territory: a systematic review and meta-analysis. Cien Saúde Coletiva 2019; 24(8):2909-22. https://doi.org/10.1590/1413-81232018248.19172017

[30] Goodarzi F, Mahvi AH, Hosseini M, Nedjat S, Nabizadeh Nodehi R, Kharazifard MJ, et al. The prevalence of dental fluorosis and exposure to fluoride in drinking water: a systematic review. J Dent Res Dent Clin Dent Prospects 2016; 10(3):127-35. https://doi.org/10.15171/joddd.2016.021

[31] Steiner M, Menghini G, Thomet E, Jäger A, Pfister J, Imfeld T. Assessment of dental fluorosis prevalence in Swiss populations. Schweiz Monatsschr Zahnmed 2010; 120(1):12-20.

[32] Castilho MCM. Efeito dos dentifrícios fluoretados sobre a prevalência de fluorose dental em uma região de água não fluoretada. [Dissertation]. Campinas: Centro de Pós-Graduação São Leopoldo Mandic; 2011. [In Portuguese].

[33] World Health Organization. Oral Health Survey: Basic Methods. 5th ed. Geneva: WHO; 2013.

[34] Ganguli M, Lytle ME, Reynolds MD, Dodge HH. Random versus volunteer selection for a community-based study. J Gerontol A Biol Sci Med Sci 1998; 53(1):M39-46. https://doi.org/10.1093/gerona/53a.1.m39

[35] Etikan I, Musa AS, Alkassim RS. Comparison of convenience sampling and purposive sampling. Am J Theor Appl Statist 2016; 5(1):1-4. https://doi.org/10.11648/j.ajtas.20160501.11

[36] Gravetter FJ, Forzano LB. Research Methods for the Behavioral Sciences. 4th ed. Boston: Cengage Learning; 2012.

[37] Trochim WMK. Research methods knowledge base. 2020. Available from: https://socialresearchmethods.net/kb/probability-sampling. [Accessed on March 11, 2020].

[38] World Health Organization. Health Research Methodology: A Guide for Training in Research Methods. 2nd ed. Manila: WHO Regional Office for the Western Pacific; 2001.

[39] Shah PB, Jha PJ. Quantitative Aptitude statistics For CACPT Examination. New Delhi: Mcgrawhill HED; 2009. pp. 275-276.

[40] Brasil. Instituto Brasileiro de Geografia e Estatística. Censo Demográfico 2010. Cidades. Available from: http://www.cidades.ibge.gov.br/xtras/perfil.php?lang=\&codmun=314000. [Accessed on March 11, 2020]. [In Portuguese].

[41] Paiva SM, Barros F, Manoel A. Contribuição ao estudo da fluorose dentária, na dentição permanente, numa comunidade com fluorose endêmica (Cocal - Urussanga - Santa Catarina). Rev Odontopediatr 1993; 2:5-12. [In Portuguese].

[42] Fejerskov O, Manji F, Baelum V, Moller IJ. Dental Fluorosis. A Handbook for Health Workers. Copenhagen: Munksgaard; 1988. 123pp.

[43] Faraco Júniro, IM, Feldens EG, Tovo MF, Sari GT. Fluorose dentária no Brasil: quadro epidemiológico atual. Rev Ibero-am Odontopediatr Odontol Bebê 2004; 7(38):387-94. [In Portuguese].

[44] Ely HC, Pretto SM. Dental fluorosis and dental caries: an epidemiologic study in cities of Rio Grande do Sul with different fluoride levels in drinking water. Rev Odonto Cienc 2000; 15(31):143-73.

[45] São Paulo. Secretaria Estadual de Saúde. Faculdade de Saúde Pública. Universidade de São Paulo. Condições de Saúde Bucal no Estado de São Paulo em 2002: Relatório Final. São Paulo: SES-SP / FSP-USP; 2002. [In Portuguese〕. 
[46] Heintze SD, Bastos JR, Bastos R. Urinary fluoride levels and prevalence of dental fluorosis in three Brazilian cities with different fluoride concentrations in the drinking water. Community Dent Oral Epidemiol 1998; 26(5):316-23. https://doi.org/10.1111/j.1600-0528.1998.tbo1967.x

[47] São Paulo. Secretaria Estadual de Saúde. Faculdade de Saúde Pública. Universidade de São Paulo. Levantamento Epidemiológico em Saúde Bucal: Estado de São Paulo, 1998: Relatório. São Paulo: SES-SP / FSP-USP; 1999. [In Portuguese].

[48] Saliba NA, Moimaz SAS, Saliba O, Santos KT, Sundfeld RH, Lelis RT. Dental fluorosis in adolescents not exposed to the fluoride water during of teeth formation. Arq Odontol 2006; 42(2):113-123.

[49] Cortes DF, Ellwood RP, O'Mullane DM, Bastos JR. Drinking water fluoride levels, dental fluorosis and caries experience in Brazil. J Public Health Dent 1996; 56(4):226-8. https://doi.org/10.1111/j.1752-7325.1996.tbo2441.x

[50] Barros SFB, Matos DL. Prevalence of dental fluorosis in 12 year-old schoolchildren, Ouro Preto/MG - 2003. Rev Bras Epidemiol 2005; 8(4):425-31. https://doi.org/10.1590/S1415-790X2005000400011

[51] Carvalho RB, Medeiros UV, Santos KT, Pacheco AC. Influence of different concentrations of fluoride in the water on epidemiologic indicators of oral health/disease. Ciênc Saúde Coletiva 2011; 16(8):3509-18. https://doi.org/10.1590/S1413-81232011000900019

[52] Aimée NR, van Wijk AJ, Maltz M, Varjão MM, Mestrinho HD, Carvalho JC. Dental caries, fluorosis, oral health determinants, and quality of life in adolescentes. Clin Oral Investig 2017; 21(5):1811-20. https://doi.org/10.1007/s00784-016-1964-3

[53] Adair PM, Pine CM, Burnside G, Nicoll AD, Gellett A, Anwar S, et al. Familial and cultural perceptions and beliefs of oral hygiene and dietary practices among ethnically and socio-economically diverse groups. Community Dental Health 2004; 21 (Supplement): 102-11.

[54] Bratthall D, Hänsel-Petersson G, Sundberg H. Reasons for the caries decline: what do the experts believe? Eur J Oral Sci 1996; 104(4):416-22. https://doi.org/10.1111/j.1600-0722.1996.tbo0104.x 